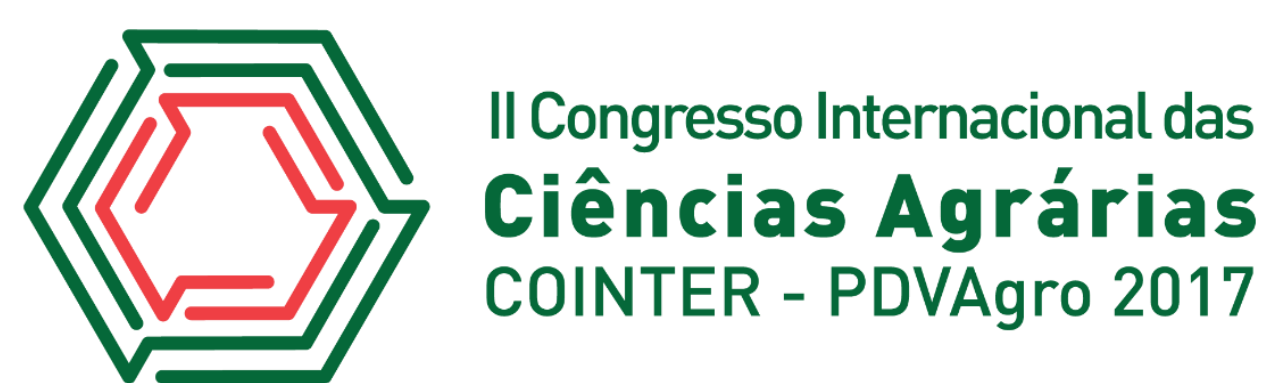

\title{
AVALIAÇÃO DO PH E DOS TEORES DE MAGNÉSIO TROCÁVEL SOB DIFERENTES COBERTURAS VEGETAIS EM LATOSSOLO AMARELO
}

\author{
Apresentação: Pôster \\ Fiama Kelly Melo Nunes ${ }^{1}$; Samara Thaís da Costa Pinheiro²; Daniela Samara Abreu das \\ Chagas ${ }^{3}$; Eduarda Gonçalves Reis ${ }^{4}$; Éder Silva de Oliveira ${ }^{5}$
}

\section{Introdução}

O magnésio $(\mathrm{Mg})$ é um nutriente essencial às plantas, sendo de suma importância para culturas agrícolas e florestais devido, principalmente, à sua função como componente da molécula de clorofila. Sua deficiência no solo e, consequentemente, nas plantas afeta significativamente a produtividade dos cultivos.

A adição de $\mathrm{Mg}$ não acontece, geralmente, por meio de fertilizantes e sim com a realização de calagem, que tem por intuito corrigir o $\mathrm{pH}$ e aumentar o teor de cálcio ( $\mathrm{Ca}$ ) e $\mathrm{Mg}$ no solo. $\mathrm{O} \mathrm{pH}$ está intimamente ligado a disponibilidade de $\mathrm{Mg}$ no solo, de modo que o aumento do $\mathrm{pH}$ a uma faixa de 5,5 a 6,5 disponibiliza teores deste elemento em quantidades satisfatórias aos plantios.

Nesse contexto, o objetivo do trabalho foi determinar os teores de $\mathrm{Mg}$ trocáveis e o $\mathrm{pH}$ do solo, sob diferentes coberturas vegetais e verificar a existência de alguma correlação entre as duas variáveis

O Mg parece estabilizar a configuração das partículas do ribossomo necessária para a síntese proteica a transferência dos aminoácidos ativados para formar a cadeia polipeptídica também necessita de $\mathrm{Mg}$

\section{Fundamentação Teórica}

A análise do solo é bastante eficiente para avaliar a reação do solo e os problemas

\footnotetext{
${ }^{1}$ Engenharia Florestal, Universidade Federal Rural da Amazônia, fiamamelo10@outlook.com

2 Engenharia Florestal, Universidade Federal Rural da Amazônia, samarathaiscosta@gmail.com

${ }^{3}$ Engenharia Florestal, Universidade Federal Rural da Amazônia, dsamaraabreu@hotmail.com

${ }^{4}$ Engenharia Florestal, Universidade Federal Rural da Amazônia, eduardagreis@gmail.com

${ }^{5}$ Doutorando, Universidade Estadual do Pará, ederso@uepa.br
} 
associados a ela, como a acidez, alcalinidade e salinidade, bem como para recomendar de forma quantitativa as medidas corretivas. A análise do solo é, também, eficaz para o fósforo, potássio, cálcio e magnésio. Nesses casos, a análise da planta se aplicaria basicamente para o acompanhamento das práticas recomendadas (FAQUIN, 2005).

O Mg ativa mais enzimas do que qualquer outro elemento (BRISKIN e POOLE, 1983). Um papel principal do elemento é ser cofator de quase todas as enzimas fosforilativas, formando uma ponte entre o pirofosfato do ATP ou ADP (tri e difosfato de adenosina, respectivamente) e a molécula da enzima.

\section{Metodologia}

A coleta de dados foi realizada na Fazenda Boa Vista, localizada no município de Abaetetuba - PA (154'30,64', S 4853'18,54', O). O relevo do terreno é relativamente plano e o solo é classificado como Latossolo amarelo distrófico com textura média. Segundo a classificação de Köppen, o clima do local, é do tipo Am, super úmido.

As amostras analisadas foram coletadas em solos sob cobertura vegetal de açaí, milho e pastagem abandonada a mais de dez anos sob regeneração natural. A amostragem das diferentes coberturas vegetais foi realizada em maio de 2017, por meio da coleta de 15 amostras simples em duas diferentes profundidades $(0-20 \mathrm{~cm}$ e $20-40 \mathrm{~cm})$, com utilização de trado sonda e trado holandês para retirada de solo. Posteriormente essas amostras foram homogeneizadas, em um recipiente limpo para evitar a contaminação do material, a fim de compor uma amostra composta.

As amostras compostas foram levadas para o laboratório de química do solo da Universidade Federal Rural da Amazônia em Belém - PA, onde obteve-se a Terra Fina Seca ao Ar (TFSA). Após esse processo o solo foi destorroado e peneirado em peneira com $2 \mathrm{~mm}$ de diâmetro para, posterior, realização da análise química do material.

A fim de demostrar a distribuição do $\mathrm{Mg}$ e a variação de $\mathrm{pH}$ na área de estudo em profundidades de 0-20 e 20-40 cm, utilizou-se o software ArcGIS 10.5.1, no laboratório de geoprocessamento da Universidade Estadual do Pará - UEPA.

A análise dos dados foi realizada no programa estatístico Assistat versão 7.7 pt (2017). O delineamento experimental foi inteiramente casualizado, em esquema fatorial $3 \times 2$, com quatro repetições, totalizando 24 parcelas amostrais, no qual os dados foram processados e submetidos ao 
teste de Tukey a 5\% de probabilidade, para comparar as médias e obter a correlação entre as variáveis mencionadas.

\section{Resultados e Discussões}

Os resultados obtidos para os teores de $\mathrm{Mg}$ trocável e a variação do $\mathrm{pH}$ demostram que em solos ácidos os teores de Mg são baixas (Tabela1).

Tabela 1: Teores de Mg trocável em Latossolo amarelo distrófico

\begin{tabular}{cccc}
\hline Tratamentos & $\begin{array}{c}\text { Prof } \\
(\mathrm{cm})\end{array}$ & $\begin{array}{c}\mathrm{pH} \\
\mathrm{H} 2 \mathrm{O}\end{array}$ & $\begin{array}{c}\mathrm{Mg} \text { troc } \\
\mathrm{cmolc} / \mathrm{dm} 3\end{array}$ \\
\hline T1 & $0-20$ & 5,21 & 0,23 \\
T2 & $20-40$ & 5,10 & 0,18 \\
T3 & $0-20$ & 5,22 & 0,23 \\
T4 & $20-40$ & 5,16 & 0,18 \\
T5 & $0-20$ & 5,23 & 0,18 \\
T6 & $20-40$ & 4,96 & 0,32 \\
\hline \multicolumn{2}{|c}{ T1 e T2: Pastagem; T3 e T4: Açaí; T5 e T6: Milho. }
\end{tabular}

Resultados semelhantes foram obtidos por Salvador et al. (2011), onde os teores de $\mathrm{Mg}$ trocáveis no solo é de 1,0 cmolc $\mathrm{kg}^{-}{ }^{1}$. Para culturas como o açaí quantidades e milho a deficiência de $\mathrm{Mg}$ trocável acarreta danos a cultura visto que há significativa diminuição na taxa de fotossíntese devido a diminuição da síntese de clorofila (STREIT et al., 2005).

A semelhança entre os teores de magnésio no solo pode ser explicada devido a baixa variação dos valores de pH (Figura 1), considerando que os mesmos estão interligados, essa correlação não é explicitada no presente estudo pois não houve significativa diferença de pH no solos sob diferentes coberturas vegetais. A prática de calagem acarretaria grandes benefícios nos diferentes tratamentos de modo a elevar o $\mathrm{pH}$ a uma faixa de no máximo 6,5 e aumentar os teores de Mg trocável. 
Figura 1: Distribuição dos valores de pH nas profundidades de 0-20 cm e 20-40 cm, na Fazenda Bela Vista. Fonte: Própria

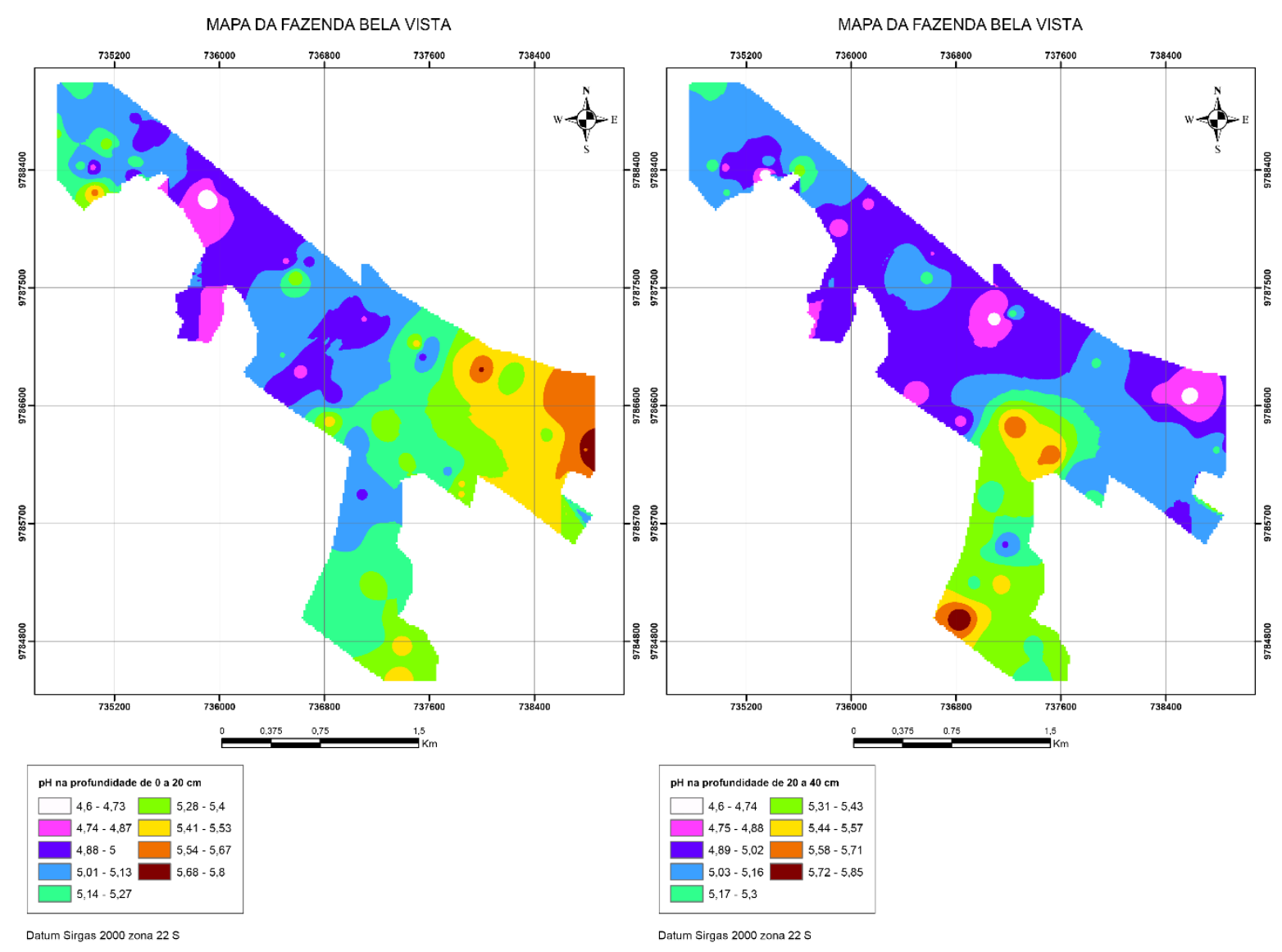

Como o magnésio não é um nutriente normalmente usado em adubações e sim nas calagens, não há muitos dados de respostas de culturas a magnésio. Contudo, deficiências têm ocorrido com uma certa frequência em solos ácidos, sendo agravados em culturas que recebem aplicações elevadas de potássio (FAQUIN, 2005).

$\mathrm{Na}$ tabela 2 é possível observar que não houve efeito significativo entre o $\mathrm{pH}$ das amostras de solo e os teores de magnésio trocável analisados. Portanto, não houve dependência ou diferenciação entre as variáveis.

Tabela 2. Análise de correlação entre as variáveis. Fonte: Própria

\begin{tabular}{ccccc}
\hline FV & GL & SQ & QM & F \\
\hline Tratamentos & 5 & 0.05668 & 0.01134 & $1.2053 \mathrm{~ns}$ \\
Resíduo & 18 & 0.16930 & 0.00941 & - \\
\hline Total & 23 & 0.22598 & - & - \\
\hline
\end{tabular}

ns: não significativo ao nível de $5 \%$ de probabilidade. 


\section{Conclusões}

Os resultados obtidos não demostraram correlação entre os teores de $\mathrm{Mg}$ trocável e o pH nas diferentes coberturas vegetais pois a variação do $\mathrm{pH}$ foi considerada baixa, em solos com significativas variações no $\mathrm{pH}$ essa correlação seria explicitada

A área estudada apresentou um solo ácido e com baixos teores de Mg isso acontece pois a disponibilidade deste nutriente é menor quanto mais baixo o valor de $\mathrm{pH}$.

\section{Referências}

BRISKIN, D. P.; POOLE, R. J. Role of magnesium in the plasma membrane ATPase of red beet. Plant Physiology, Washington, v. 71, n. 4, p. 969-971, Dec. 1983.

FAQUIN, V. Nutrição Mineral de Plantas. Lavras: UFLA / FAEPE, 2005. p. 186. - Curso de PósGraduação "Lato Sensu” (Especialização) a Distância: Solos e Meio Ambiente.

SAlVADOR, J. T., CARVAlHO, T. C., LUCCHES, L. A. C. Relações cálcio e magnésio presentes no solo e teores foliares de macronutrientes. Rev. Acad., Ciênc. Agrária Ambient., Curitiba, v. 9, n. 1, p. 27-32, 2011.

STREIT, Nivia Maria et al . As clorofilas. Cienc. Rural, Santa Maria , v. 35, n. 3, p. 748-755, 2005 . 